PREPARED FOR THE U.S. DEPARTMENT OF ENERGY, UNDER CONTRACT DE-AC02-76CH03073

PPPL-3764

PPPL-3764

UC-70

\title{
Configuration and Heating Power Dependence of Edge Parameters and H-mode Dynamics in National Spherical Torus Experiment (NSTX)
}

by

C.E. Bush, M.G. Bell, R.E. Bell, J. Boedo, E.D. Fredrickson, S.M. Kaye, S. Kubota, B.P. LeBlanc, R. Maingi, R.J. Maqueda, S.A. Sabbagh,

V.A. Soukhanovskii, D. Stutman, D.W. Swain, J.B. Wilgen, S.J. Zweben, W.M. Davis, D.A. Gates, D.W. Johnson, R. Kaita, H.W. Kugel, D. Mastrovito, S. Medley, J.E. Menard, D. Mueller, M. Ono, F. Paoletti, S.J. Paul, Y-K.M. Peng, R. Raman, P.G. Roney, A.L. Roquemore, C.H. Skinner, E.J. Synakowski, and G. Taylor for the NSTX Team

January 2003
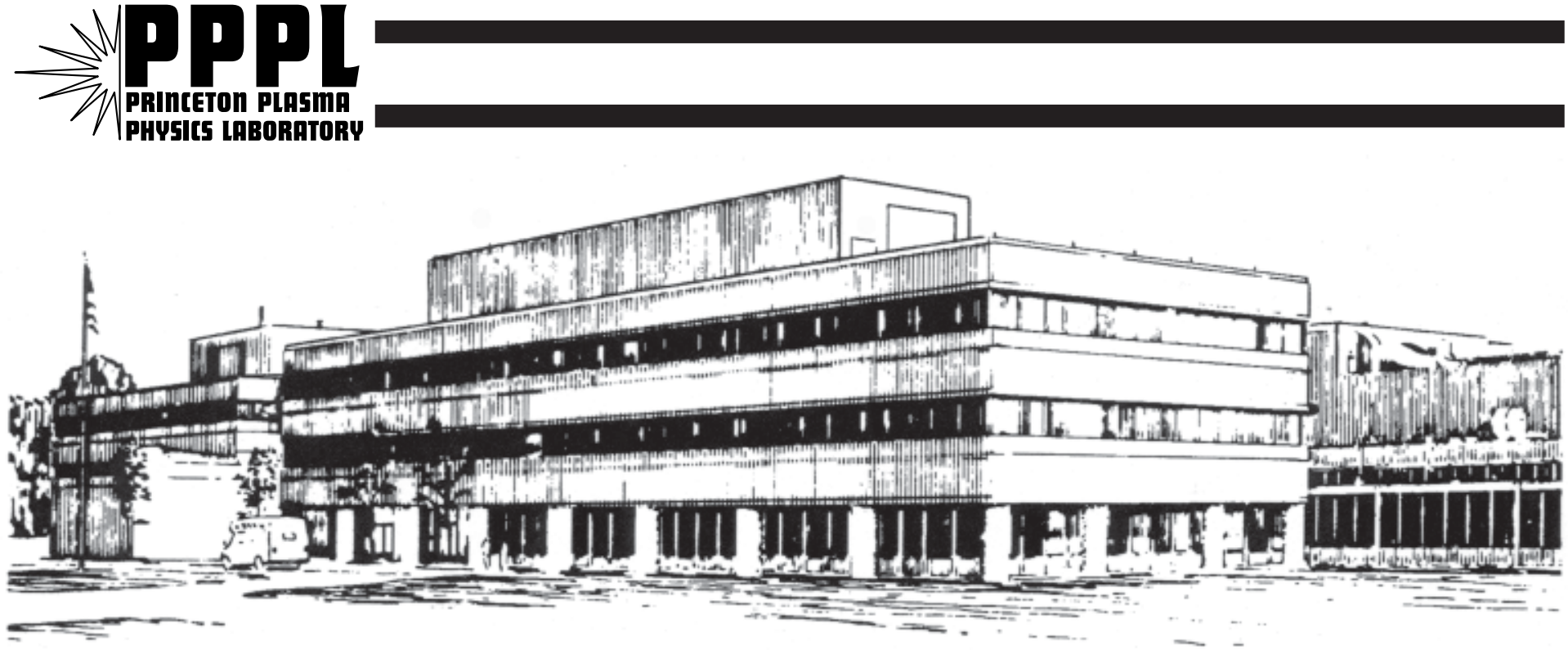
PRINCETON UNIVERSITY, PRINCETON, NEW JERSEY 


\section{PPPL Reports Disclaimer}

This report was prepared as an account of work sponsored by an agency of the United States Government. Neither the United States Government nor any agency thereof, nor any of their employees, makes any warranty, express or implied, or assumes any legal liability or responsibility for the accuracy, completeness, or usefulness of any information, apparatus, product, or process disclosed, or represents that its use would not infringe privately owned rights. Reference herein to any specific commercial product, process, or service by trade name, trademark, manufacturer, or otherwise, does not necessarily constitute or imply its endorsement, recommendation, or favoring by the United States Government or any agency thereof. The views and opinions of authors expressed herein do not necessarily state or reflect those of the United States Government or any agency thereof.

\section{Availability}

This report is posted on the U.S. Department of Energy's Princeton Plasma Physics Laboratory Publications and Reports web site in Fiscal Year 2003. The home page for PPPL Reports and Publications is: http://www.pppl.gov/pub_report/

DOE and DOE Contractors can obtain copies of this report from:

U.S. Department of Energy

Office of Scientific and Technical Information

DOE Technical Information Services (DTIS)

P.O. Box 62

Oak Ridge, TN 37831

Telephone: (865) 576-8401

Fax: (865) 576-5728

Email: reports@adonis.osti.gov

This report is available to the general public from:

National Technical Information Service

U.S. Department of Commerce

5285 Port Royal Road

Springfield, VA 22161

Telephone: $1-800-553-6847$ or

(703) $605-6000$

Fax: (703) 321-8547

Internet: http://www.ntis.gov/ordering.htm 


\section{Configuration and Heating Power Dependence of Edge Parameters and H-mode Dynamics in National Spherical Torus Experiment (NSTX)}

C.E. Bush 1), M.G. Bell 2), R.E. Bell 2), J. Boedo 3), E.D. Fredrickson 2), S.M. Kaye 2), S. Kubota 4), B.P. LeBlanc 2), R. Maingi 1), R.J. Maqueda 5), S.A. Sabbagh 6), V.A. Soukhanovskii 2), D. Stutman 7), D.W. Swain 1), J.B. Wilgen 1), S.J. Zweben 2), W.M. Davis 2), D.A. Gates 2), D.W. Johnson 2), R. Kaita 2), H.W. Kugel 2), D. Mastrovito 2), S. Medley 2), J.E. Menard 2), D. Mueller 2), M. Ono 2), F. Paoletti 6), S.J. Paul 2), Y-K.M. Peng 1), R. Raman 8), P.G. Roney 2), A.L. Roquemore 2), C.H. Skinner 2), E.J. Synakowski 2), G. Taylor 2) for the NSTX Team

1) Oak Ridge National Laboratory, Oak Ridge, Tennessee 37831

2) Princeton Plasma Physics Laboratory, Princeton University, Princeton, New Jersey 08543

3) University of California, San Diego, San Diego California

4) University of California at Los Angeles, Los Angeles, California

5) Los Alamos National Laboratory, Los Alamos, New Mexico 87545

6) Columbia University, New York, New York 10027

7) Johns Hopkins University, Baltimore, Maryland

8) University of Washington, Seattle, Washington 98195

E-mail address of first author: bushce@ ornl.gov

Abstract. Edge parameters play a critical role in H-mode access, which is a key component of discharge optimization in present day toroidal confinement experiments and the design of next generation devices. Because the edge magnetic topology of a spherical torus (ST) differs from a conventional aspect ratio tokamak, H-modes in STs exhibit important differences compared with tokamaks. The dependence of the NSTX edge plasma on heating power, including the L-H transition requirements and the occurrence of edge-localized modes (ELMs), and on divertor configuration is quantified. Comparisons between good L-modes and H-modes show greater differences in the ion channel than the electron channel. The threshold power for the H-mode transition in NSTX is generally above the predictions of a recent ITER scaling. Correlations of transition and ELM phenomena with turbulent fluctuations revealed by Gas Puff Imaging (GPI) and reflectometry are observed. In both 
single null and double-null divertor discharges, the density peaks off-axis, sometimes developing prominent "ears" which can be sustained for many energy confinement times, $\tau_{\mathrm{E}}$, in the absence of ELMs. A wide variety of ELM behavior is observed, and ELM characteristics depend on configuration and fueling.

\section{Introduction:}

A main goal of the National Spherical Torus Experiment (NSTX) [1] is to assess the attractiveness of the spherical torus (ST) for pulse lengths longer than current diffusion times. This is important since one possible advantage of operation at low aspect ratio, $\mathrm{A} \equiv \mathrm{R} / \mathrm{a}$, would be a smaller size, and in turn, a lower cost reactor concept. H-mode studies are important to this goal since their profiles provide the stability needed for high $\beta$ long pulse operation.

Recent operation of NSTX resulted in rapid progress in increasing performance [2-4]. This was accomplished through reduction of intrinsic magnetic field errors, improvements in machine conditioning techniques, and development of operational scenarios with gas puffing from the center stack. As a result, H-mode access and reproducibility were improved substantially.

The main advantages of the H-mode are broad density, temperature and pressure profiles. Use of the H-mode has allowed rapid progress in increasing the toroidal beta $\left(\beta_{\mathrm{T}}\right)$

up to $35 \%$ [5], where $\beta_{\mathrm{T}}=\langle\mathrm{p}\rangle /\left(\mathrm{B}_{\mathrm{T} 0}{ }^{2} / 2 \mu_{0}\right)$, due to the reduced pressure peaking factor and improved energy confinement. H-modes have also helped in sustaining high $\beta_{\mathrm{T}} \sim 21 \%$ for $500 \mathrm{~ms}$, as a result of reduced volt-second consumption because of high bootstrap fraction. 
In order to utilize H-modes to achieve the goals of NSTX, experiments were conducted to determine the parametric and configurational dependencies of the $\mathrm{L}-\mathrm{H}$ power threshold and occurrence of edge-localized-modes (ELMs). This paper describes the Hmode operating window, power threshold studies, fluctuation studies, and ELM experiments.

\section{Description of Experiment and H-Mode Parameter Range:}

The H-mode results reported here were all for plasmas for which only neutral beam injection, NBI, auxiliary heating was used. RF H-mode results were reported elsewhere [6]. H-modes were obtained in both lower single null divertor (LSN) and double null divertor (DN) configurations. The majority was LSN but the DN configuration is finding increasing usage because of access to higher $\mathrm{I} / \mathrm{aB}$, and thus higher absolute $\beta_{\mathrm{T}}$. However, it was observed that higher power was required to access DN H-modes. During the most recent experimental campaign, no effort was made to obtain $\mathrm{H}$-modes using the upper single null configuration. Also, a dedicated effort has not been made to obtain ohmically heated $(\mathrm{OH})$ or center-stack limited H-modes. No H-modes were obtained in any of these three cases.

$\beta$ limit studies were done mainly in the double-null divertor configuration, and pulse length extension studies in the lower single null configuration. Heating power included up to $7 \mathrm{MW}$ of neutral beam injection, NBI, and $6 \mathrm{MW}$ of high harmonic fast wave, HHFW, radio frequency $(R F)$ power. The lowest aspect ratio, $A \equiv R / a$, achieved was $\geq 1.27$ for $R=0.8 \mathrm{~m}$ and $\mathrm{a}=0.67 \mathrm{~m}$; more typically, $\mathrm{A} \sim 1.4-1.5$ for H-mode discharges with inner wall gap $\sim 10$ $\mathrm{cm}$. The parameter ranges for access to H-modes in NSTX were wide, and this can be seen from Figure 1, where plots of $B_{T}$ vs $I_{p}\left[\right.$ Fig. 1(a)] and $P_{N B I}$ vs $n_{e}$ are shown. Here, $n_{e}$ was the line-averaged density at the time of the L-H transition. From Fig. 1(a) one can see the ranges 
for $\mathrm{I}_{\mathrm{p}}$ and $\mathrm{B}_{\mathrm{T}} ; 0.6 \leq \mathrm{I}_{\mathrm{p}} \leq 1.3 \mathrm{MA}$ and $0.3 \leq \mathrm{B}_{\mathrm{T}} \leq 0.6 \mathrm{~T}$. The beam power was varied from a low of $320 \mathrm{~kW}$ to a high of 22 times this value, i.e. $7 \mathrm{MW}$. The range of plasma line averaged densities was $1.5 \leq \mathrm{n}_{\mathrm{e}} \leq 4.8 \times 10^{19} / \mathrm{m}^{3}$ (at the L-H time). In addition $\beta_{\mathrm{T}} \sim 35 \%$ and $\beta_{\mathrm{p}} \sim 1.4$ were obtained, and the maximum H-mode phase duration was $\sim 500 \mathrm{~ms}$ (with NBI). The database plotted in Fig. 1 contains more than 500 H-mode plasmas.

The rapid progress in NSTX performance was made possible by a wall-conditioning regimen [7] consisting of a $350^{\circ} \mathrm{C}$ bake-out, followed by boronization, and between shot helium glow discharge cleaning. Use of high field side (HFS) gas puff fueling served to increase ease of access to the H-mode just as was observed earlier on MAST [8]. The results for an HFS vs LFS H-mode access experiment in NSTX were recently reported [9]. It was found during HFS fueling studies that at too high a gas puff rate, H-modes did not occur, and at too low a flow rate, low density locked modes and reconnection events occurred.

A very important result for the NSTX H-mode was that not only was high performance achieved, but it could also be sustained during long duration $\mathrm{H}$-modes. Figure 2 shows a long pulse (>700 ms) discharge where the L-H transition took place at $230 \mathrm{~ms}$ and the H-mode duration was $\sim 500 \mathrm{~ms}$. Through the duration of the H-mode, the stored energy [Figure 2(c)] plateaued at $\mathrm{W}_{\mathrm{MHD}}=250 \mathrm{~kJ}$. The energy confinement enhancement factor $\mathrm{H}_{98 \mathrm{pby} 2}$ over the predictions of the ITER-98P ELMY H-mode scaling [10] remained at a steady state value of 1.5 . Figure 2(b) shows that the line averaged density increased during the H-mode reaching a value of $6 \times 10^{19} / \mathrm{m}^{3}$. Note that the radiated power, $\mathrm{P}_{\text {rad }}$, Figure $2(\mathrm{~b})$ was fairly constant during the long duration H-mode phase, indicating that there was no significant core impurity accumulation. 
One benefit of the long duration H-mode was the ability to observe profile evolution. Early NSTX H-modes [11,12] were too short for such observations. For the long pulse high performance $\mathrm{H}$-mode of Figure 2 we see that the $\mathrm{n}_{\mathrm{e}}$ and $\mathrm{T}_{\mathrm{e}}$ profiles evolved differently. The $n_{e}$ profile of Figure 3(a) shows the usual L-mode edge at $t=0.227 \mathrm{~s}$. At the transition the edge $n_{e}$ pedestal rose rapidly, developing an off-axis peak or "ears" [13] by $t=0.260 \mathrm{~s}$. The early profiles were hollow. The $n_{e}$ profile evolved with the core filling in faster than the edge, and finally becoming flat with no "ear' features. In general, the $n_{e}$ profile filled in within 300 to $500 \mathrm{~ms}$. On the other hand, the $\mathrm{T}_{\mathrm{e}}$ profile, Figure 3(b), was flattened and broadened significantly $(\mathrm{t}=0.26 \mathrm{~s})$ just after the transition. Initially it remained broad but later became peaked. The flat $\mathrm{n}_{\mathrm{e}}$ profile and broad $\mathrm{T}_{\mathrm{e}}$ profile resulted in a broad pressure profile with low pressure peaking factor $\mathrm{F}_{\mathrm{p}}=\mathrm{p}_{\mathrm{e}}(0) /\left\langle\mathrm{p}_{\mathrm{e}}\right\rangle \leq 2$. The NSTX H-mode developed a very steep electron density gradient at the edge that evolved rapidly at the L-H transition. A fast scanning edge reflectometer was used on NSTX to follow the dynamics of the edge density with much better time resolution than available with the Thomson scattering diagnostic. The steep density gradient was consistent with the concept of an edge transport barrier. At the steep gradient position, the ultra soft X-ray (USXR) array often showed accumulation of carbon. However, there often was no evidence for accumulation of impurities inside the edge barrier.

In NSTX both L-mode and H-mode plasmas achieved good confinement reproducibly. This is shown in Figure 4, which is a plot of $\tau_{\mathrm{E}}{ }^{\mathrm{NSTX}}$ vs $\tau_{\mathrm{E}}{ }^{97 \mathrm{~L}}[14,6]$ where the experimental values were taken at times when the plasma was in quasi steady state. Both Lmodes and H-modes occurred throughout the range of $0.75 \leq \tau_{\mathrm{E}}{ }^{\mathrm{NSTX}} / \tau_{\mathrm{E}}{ }^{97 \mathrm{~L}} \leq 2.5$, with a maximum measured confinement time of $110 \mathrm{~ms}$. 
Normally in NSTX, the gain in confinement time following a transition from the usual L-mode confinement (i.e. $97 \mathrm{~L}$-mode scaling) to $\mathrm{H}$-mode was $>50 \%$, as in conventional aspect ratio tokamaks. In NSTX, it was of interest to capitalize on the high performance L-mode by obtaining the same percentage gain in performance from $\mathrm{L}$ to $\mathrm{H}$. However, very often the gain in going from a high performance L-mode to H-mode was rather modest. An example of this behavior is the discharge [3] of Figure 5, for which the time variation of $\mathrm{I}_{\mathrm{p}}$ and $\mathrm{P}_{\mathrm{NBI}}$ [Figure 5(a)], $\beta_{\mathrm{T}}$ [Figure $5(\mathrm{~b})$ ], and $\tau_{\mathrm{E}}$ and $\mathrm{D}_{\alpha}$ [Figure 5(c)] are plotted. In this case, the L-H transition was late in the discharge $(\sim 0.34 \mathrm{~s})$ and the L-mode performance at the time of transition was high. At the transition there was a transient increase in $\tau_{\mathrm{E}}$ which quickly rolled over; $\beta_{\mathrm{T}}$ increased from $\sim 13 \%$ before the transition to a final plateau value of $\sim 16 \%$ during the $\mathrm{H}$-mode phase. Possible explanations for the reduced gain in performance are based on profile effects and MHD activity.

Additional insight was obtained by comparing plasma profiles before and after the L$\mathrm{H}$ transition (Figure 6). A big difference appeared to be in the ion channel, based on $\mathrm{T}_{\mathrm{i}}$ and $\mathrm{V}_{\phi}$ profiles from the charge exchange recombination spectroscopy (CHERS) diagnostic. The profiles for the electron channel, $\mathrm{n}_{\mathrm{e}}$ and $\mathrm{T}_{\mathrm{e}}$ are plotted in Figures 6(a) and (b). The edge density gradient $\nabla \mathrm{n}_{\mathrm{e}}$ was high and the pedestal $\mathrm{n}_{\mathrm{e}}$ in the H-mode phase was $\sim 4$ times the Lmode edge value. The $\mathrm{H}$-mode $\mathrm{n}_{\mathrm{e}}$ profile was rather flat. There was little difference in the $T_{e}$ profiles in general, though, the inner (high field side) $\mathrm{T}_{\mathrm{e}}$ went from $100 \mathrm{eV}$ in L-mode to 200 $\mathrm{eV}$ in $\mathrm{H}$-mode. The $\mathrm{H}$-mode $\mathrm{T}_{\mathrm{e}}$ profile was also rather flat. On the other hand, the $\mathrm{T}_{\mathrm{i}}$ and $\mathrm{V}_{\phi}$ profiles [Fig 6(c) and 6(d)] were dramatically different. The $T_{i}$ profile went from peaked to flat with a much steeper edge gradient, $\nabla \mathrm{T}_{\mathrm{i}}$, with a decrease in the core from $1.7 \mathrm{keV}$ to 1.1 $\mathrm{keV}$. Similarly the $\mathrm{V}_{\phi}$ profile went from centrally peaked to flat and a central value of 170 
$\mathrm{km} / \mathrm{s}$ in the L-mode plasma to $\sim 100 \mathrm{~km} / \mathrm{s}$ in the H-mode phase with a steep edge gradient. Possible explanations for the resulting profiles in the H-phase include triggering of MHD modes soon after the transition that effectively increased the core transport. These cases were not fully understood and will require further study.

\section{Power threshold studies on NSTX:}

The L-H threshold power requirements for obtaining H-modes were determined for a number of parameter/configuration combinations in NSTX. This was done in a series of dedicated experiments involving scans in $\mathrm{P}_{\mathrm{NBI}}, \mathrm{I}_{\mathrm{p}}, \mathrm{B}_{\mathrm{T}}$, and $\mathrm{n}_{\mathrm{e}}$ and in the divertor configuration. In addition, the physics of the $\mathrm{L}-\mathrm{H}$ transition and the resulting characteristics of the H-mode and ELMs, were investigated as part of the power threshold experiments.

The L-H power threshold was found by reducing $\mathrm{P}_{\mathrm{NBI}}$ for a set $\mathrm{I}_{\mathrm{p}}, \mathrm{B}_{\mathrm{T}}$, and $\mathrm{n}_{\mathrm{e}}$ until no $\mathrm{L}-\mathrm{H}$ transition occurred. The indicators for being near the threshold were very short Hmodes or dithers as observed in the $\mathrm{D}_{\alpha}$ signal. Parameters for discharges of a representative threshold determination are shown in Fig.7. In this case $\mathrm{I}_{\mathrm{p}}$ and $\mathrm{B}_{\mathrm{T}}$ were $0.9 \mathrm{MA}$ and $0.45 \mathrm{~T}$ respectively. Shown are time traces of $\mathrm{I}_{\mathrm{p}}$ [Fig. 7(a)], $\mathrm{P}_{\mathrm{NBI}}$ [Fig. 7(b)], and $\mathrm{D}_{\alpha}$ [Fig. 7(c)]. Four discharges [indicated by $1-4$ in Fig 7(b)] of the beam power scan are presented in the figure, for three different power levels; $0.675,1.146$, and $1.636 \mathrm{MW}$. The power scan began at $\mathrm{P}_{\mathrm{NBI}}=1.636 \mathrm{MW}$, using a single beam source full on at a beam voltage of $80 \mathrm{kV}$, which was far above the threshold. The beam voltage was decreased to obtain the power levels shown in Fig. 7(b). The L-H transition, as indicated by the drop in the $\mathrm{D}_{\alpha}$ emission, took place at essentially the same time of $0.210 \mathrm{~ms}$ for the three shots that showed transitions, well after the NBI turn-on time. At the lowest $\mathrm{P}_{\mathrm{NBI}}(0.675 \mathrm{MW})$, one discharge had a short $\mathrm{H}-$ 
mode and the other no $\mathrm{H}$-mode at all. This was taken to be an indication that $0.675 \mathrm{MW}$ was the $\mathrm{P}_{\mathrm{NBI}}$ required essentially at or very close to the threshold power. A trend evident in Figure 7 (c) is that the duration of the H-mode increased with power above the threshold, going from $\sim 7 \mathrm{~ms}$ near the threshold to $50 \mathrm{~ms}$ at nearly twice $(5 / 3)$ the threshold power and $\geq 90 \mathrm{~ms}$ at the highest power (2.4 times $\mathrm{P}_{\mathrm{NBI}}$ at the threshold).

The example of Fig. 7 included many of the main components of the threshold determination procedure in NSTX. However, since only one beam source was required, the full means of controlling the range in power possible could not be demonstrated in Fig 7. The extremely wide range in $\mathrm{P}_{\mathrm{NBI}}$ of $320 \mathrm{~kW}$ to $7 \mathrm{MW}$ [Fig. 1(a)] was obtained using a combination of varying the number of beam sources from 1 to 3 , varying the beam voltage from $\sim 45 \mathrm{kV}$ to $\sim 100 \mathrm{kV}$ and finally by beam modulation. For the low value of $320 \mathrm{~kW} \mathrm{a}$ low beam voltage of $55 \mathrm{kV}$ was used and a single source was modulated using a $50 \%$ duty cycle of $10 \mathrm{~ms}$ beam on and $10 \mathrm{~ms}$ beam off. Usually as the power was increased above the threshold, the transition time shifted forward to an earlier time, consistent with easier access to the H-mode at the higher power levels.

The power threshold on NSTX has an apparent current dependence. This was seen from determinations of $\mathrm{P}_{\mathrm{th}}$ at two different currents, 600 and $900 \mathrm{kA}$ respectively both at a $\mathrm{B}_{\mathrm{T}}$ $=0.45 \mathrm{~T}$ and use was made of the techniques presented in discussing Fig 7. Results for this comparison are shown in Figure 8, where the time variation of $\mathrm{I}_{\mathrm{p},} \mathrm{P}_{\mathrm{NBI}}$, and $\mathrm{D}_{\alpha}$ are given for the two cases. Modulated beam power was used to lower $\mathrm{P}_{\mathrm{NBI}}$ sufficiently to obtain the result for the $600 \mathrm{kA}$ case as can be seen in Figure 8 (c). The very short H-mode phases were taken as evidence that the power was close to the threshold in each case. $\mathrm{P}_{\mathrm{NBI}}$ required at the threshold were $320 \mathrm{~kW}$ at $600 \mathrm{kA}$ and $660 \mathrm{~kW}$ at $900 \mathrm{kA}$ ). 
The NSTX L-H threshold powers for the discharges of Fig. 8 can be compared to values given by scalings derived from conventional aspect ratio tokamak data contained in the international L-H threshold database. The most recent scaling was given by $\mathrm{P}_{\mathrm{th}, 1} \sim$ $\mathrm{n}_{\mathrm{e}}^{0.61} \mathrm{~B}_{\mathrm{T}}^{0.78} \mathrm{a}^{0.89} \mathrm{R}^{0.94}[15]$. The experimental loss power, $\mathrm{P}_{\mathrm{LOss}}=\mathrm{P}_{\mathrm{OH}}+\mathrm{P}_{\mathrm{NBI}}-\mathrm{dW} / \mathrm{dt}-\mathrm{P}_{\mathrm{FLOSS}}$, (where $\mathrm{P}_{\mathrm{FLOSS}}$ included the total fast ion loss power as calculated by TRANSP) was normalized to the above scaling for $\mathrm{P}_{\mathrm{th}, 1}$ and plotted versus $\mathrm{I}_{\mathrm{p}}$ in Fig. 9 along with other Lmode and $\mathrm{H}$-mode data near the threshold. In the Figure, $\mathrm{P}_{\text {Loss }}$ values ranged from $96 \mathrm{~kW}$ for $I_{p}=600 \mathrm{kA}$ to $230 \mathrm{~kW}$ for 1 MA. As seen from Fig. 9, the threshold power levels for NSTX H-modes were higher than those predicted by the scalings, even though the actual values of $\mathrm{P}_{\mathrm{NBI}}$ were rather modest. The ratio at $600 \mathrm{kA}$ was $\mathrm{P}_{\mathrm{LOSS}} / \mathrm{P}_{\mathrm{th}, 1} \sim 2.5$, i.e. the threshold level for NSTX was 2.5 times $\mathrm{P}_{\mathrm{th}, 1}$. At $900 \mathrm{kA}$ the ratio was $\sim 6.3$. These results indicate the importance of including the NSTX data to determine explicit aspect ratio dependence in future threshold scalings.

The threshold studies showed that there were other factors that affected the L-H transition power threshold on NSTX which have yet to be fully understood. These factors included wall conditioning, plasma impurity content, and fueling rate and location. For $\mathrm{I}_{\mathrm{p}}=$ $900 \mathrm{kA}$, the NBI power required at threshold was reduced from $830 \mathrm{~kW}$ to $660 \mathrm{~kW}$ following $350^{\circ} \mathrm{C}$ bake-out, boronization, and error field correction.

To complete the picture of the threshold power behavior on NSTX, the L-H transition data was compared to key physics parameters from three different L-H transition theories [16]. They were the (1) drift-ballooning [17], (2) peeling [18], and (3) drift-Alfven mode [19] theories. For all three theories it was found that H-mode points were well separated from L-mode points due mainly to decreased density gradient scale length and increased $\beta$ in 
the H-mode. The groupings were separated in parameter space in qualitative agreement with expectations from the theories. The NSTX H-mode threshold studies will continue during the next experimental campaign.

\section{Fluctuations before during and after the L-H transition:}

Fluctuations were reduced in the edge plasma at the transition and during the $\mathrm{H}$ mode, including the scrape off layer (SOL) and the steep density gradient regions. Fluctuation data for the SOL were provided by the gas puff imaging (GPI) diagnostic [20], the reciprocating edge probe, and the broadband 6 to $26 \mathrm{GHz}(6-26 \mathrm{GHz})$ reflectometer [21]. Data for the steep density gradient region was provided by the edge scanning reflectometer. Figure 10 shows density fluctuation power spectra from the $6-26 \mathrm{GHz}$ reflectometer for the L-mode and H-mode phases of a typical discharge. Comparison of the two spectra taken in the SOL, where $\mathrm{T}_{\mathrm{e}}<20 \mathrm{eV}$ and $\mathrm{n}_{\mathrm{e}}<3 \times 10^{12} / \mathrm{cm}^{3}$, demonstrated that the turbulence was reduced in the SOL during the H-mode. The H-mode spectrum was far below that for the Lmode for the full frequency range shown; 10 to $500 \mathrm{kHz}$. The greatest difference was in the 100 to $500 \mathrm{kHz}$ range with a difference of greater than two orders of magnitude at $300 \mathrm{kHz}$. A strong coherent mode at a frequency slightly greater than $100 \mathrm{kHz}$ was evident in the $\mathrm{H}$ mode spectrum.

The fast edge scanning reflectometer [22] also showed fluctuations to be reduced after the L-H transition. Figure 11 shows the results for this diagnostic. Spectrograms of the density fluctuations are shown at 3 different density locations (cutoffs); $3.8 \times 10^{12} / \mathrm{cm}^{3}$ ( $\mathrm{f}=$ 17.6 GHz), $9.9 \times 10^{12} / \mathrm{cm}^{3}(\mathrm{f}=28.2 \mathrm{GHz})$, and $3.1 \times 10^{13} / \mathrm{cm}^{3}(\mathrm{f}=50 \mathrm{GHz})$. At the transition, all three spectrograms showed an instantaneous reduction in the fluctuations for frequencies 
above approximately $50 \mathrm{kHz}$. All three spectrograms showed a temporary return of fluctuations due to an event (most likely an ELM) at $\sim 0.334 \mathrm{~s}$. At the steep density gradient position at $\sim 1 \times 10^{13} / \mathrm{cm}^{3}$ the power spectrum for the H-mode phase $(0.340-0.345 \mathrm{~s})$ was an order of magnitude lower than the spectrum for the L-mode phase $(0.325-0.330 \mathrm{~s})$ through the full frequency range studied of $5 \mathrm{kHz}$ to $1 \mathrm{MHz}$. This was found in the power spectra of the two cases but is not shown here. The H-mode spectrum showed an intermittent coherent mode at high frequency, 120 to $150 \mathrm{kHz}$, similar to the coherent mode centered at $\sim 120 \mathrm{kHz}$ in the spectrum for the $6-26 \mathrm{GHz}$ reflectometer.

The edge turbulence in the scrape off layer (SOL) during H-modes in NSTX was also measured using Gas Puff Imaging (GPI) [20], in which the neutral line emission from a helium gas puff was imaged to determine the local space-time structure of the edge turbulence. In these experiments the gas injected was He and the HeI $(587.6 \mathrm{~nm})$ line was used for imaging. The temporal evolution of the 2-D turbulence was measured within a 30 $\mathrm{cm}$ poloidal by $15 \mathrm{~cm}$ radial area centered $17^{\circ}$ above the outer midline using a PSI-4 ultrahigh speed camera [23]. This was supplemented by time series data from discrete chord fiber optic arrays located within the image.

Normally, based on GPI data L-mode (and Ohmic) plasmas showed a complicated structure in the edge region, whereas H-mode plasmas normally have a less turbulent structure. A comparison of the poloidal k-spectrum, from GPI, of an H-mode and an L-mode discharge showed the $\mathrm{k}$-spectra to be similar, but with the fluctuation level $\approx 3-4$ times lower in the H-mode as compared to that in the L-mode.

Just as in L-mode plasmas, H-modes can have localized "blobs" moving radially or poloidally within the edge region, similar to structures recently seen at Alcator C-Mod [24]. 
These blobs appeared as local maxima in the 2-D images and as large transient spikes in the discrete chord time series. It is interesting to note that these transient spikes were apparently not related to the ELMs that occurred during NSTX H-mode plasmas, since the spikes seen in the GPI chord signals could occur between ELMs (and seemed to be reduced during ELMs). Similar intermittent events caused significant local particle transport during the $\mathrm{H}$ mode in DIII-D [25].

\section{ELM behavior and characteristics in NSTX:}

ELMs are of interest to NSTX for several reasons. First, determining and quantifying their effects on the plasma itself may help to gain an understanding of ELM physics. Second, ELM behavior must be controlled in order to employ them to modify plasma properties, e.g. restricting core impurity accumulation, and edge density control. Third, and associated most with fundamental physics of H-modes, were the ELM effects on the edge pedestal. Recent studies in tokamaks showed that the edge pedestal (n, T, p) affects the core confinement in a dynamic fashion. Changes in edge pedestal height and width impacted core confinement essentially instantaneously. Therefore, the ELM studies included preliminary determination of the parametric dependence of ELM perturbations such as $\Delta \mathrm{n}_{\mathrm{e}} / \mathrm{n}_{\mathrm{e}}, \Delta \mathrm{T}_{\mathrm{e}} / \mathrm{T}_{\mathrm{e}} \Delta \mathrm{T}_{\mathrm{i}} / \mathrm{T}_{\mathrm{i}}$, $\Delta \mathrm{V}_{\phi} / \mathrm{V}_{\phi}$ and $\Delta \mathrm{W} / \mathrm{W}$ at each ELM. Machine parameters, $\mathrm{I}_{\mathrm{p},}, \mathrm{B}_{\mathrm{t}}, \mathrm{n}, \mathrm{T}$ and $\mathrm{V}_{\mathrm{p}}$ affect the size and radial extent of ELM perturbations. As a component of the push to higher $\beta$ operation, one strategy would be to tailor the ELM size and frequency to modulate the edge pressure without significant de-rating of the overall plasma performance. This could help to avoid exceeding stability limits that lead to large ELMs that dump large portions of plasma particles and energy and cause localized wall heat loading (hot spots) of the wall. So far, 
there appear to be few qualitative differences in ELM behavior between low aspect ratio ST's and conventional aspect ratio tokamaks.

A variety of ELMs were observed on NSTX, and ELMs were obtained in both LSN and DN divertor configurations. DN divertor plasmas ELM easily while LSN divertor plasmas do not. Very often, the LSN H-modes were ELM free or have long period intermittent giant ELMs.

On NSTX the ELM behavior depended on operating conditions and divertor configuration. Factors that influenced ELM behavior included, edge density and temperature, toroidal field, heating power magnitude and type, gas puff flow rate, and magnetic geometry. This is illustrated in Fig. 12, which shows the ELM behavior for three different discharges.

Figures 12(a) and (b) show two different types of ELM behavior in the LSN divertor configuration, and Fig 12(c) is a DN divertor example. In Fig 12(a) the $\mathrm{D}_{\alpha}$ signal shows the plasma was virtually ELM free. However, there were high frequency fluctuations that were superimposed on the $\mathrm{D}_{\alpha}$ signal for the duration of the H-mode. We have not yet conclusively identified if the fluctuations were high frequency grassy ELMs or oscillations similar to observations during high performance plasmas in conventional aspect ratio tokamaks.

Giant ELMs occurred in the second LSN case, which had, among other differences, a lower fueling rate. In the third case, for the DN divertor, the ELM frequency was high and the amplitude modest. A database of ELM parameters was assembled and in general it was found that ELM amplitude decreased with increasing frequency. This is evident in Fig. 13, which is a plot of the amplitude of the $\mathrm{D}_{\alpha}$ burst, $\Delta \mathrm{D}_{\alpha}$, during an ELM, versus frequency $v_{\mathrm{ELM}}$. Here, $v_{\mathrm{ELM}}$ is $1 / \Delta \mathrm{t}$ ELM to ELM. As shown in Fig. $13, \Delta \mathrm{D}_{\alpha}$ decreased strongly as $v_{\mathrm{ELM}}$ 
increased. This frequency behavior is consistent with Type I ELMs on conventional tokamaks. Different from conventional aspect ratio tokamaks, the giant ELMs were observed in the highest $\beta$ discharges (high $\delta$, DN divertor). Usually high performance discharges had the largest ELMs.

The ELM size and frequency also affected the extent to which the H-mode character was temporarily lost afterwards. Large ELMs as in Figure 12(b) very often appeared to return confinement to L-mode. In fact, the L-mode edge immediately following the ELM seemed to cause an instant transition back to the $\mathrm{H}$-mode, with the $\mathrm{D}_{\alpha}$ signal falling below its original level just before the ELM (H-mode phase) as seen just after the three large ELMs of Figure 12 (b). The fourth burst on the $\mathrm{D}_{\alpha}$ trace was the result of an internal mode that destroyed confinement and terminated the H-mode. For more modest ELMs, as in Figure 12(c), the effect was restricted to a thin shell of plasma and performance was only slightly reduced relative to ELM-free operation. It is important to note that a much wider variety of ELM behavior was observed on NSTX than illustrated in Figure 12.

For a plasma in which a single giant ELM occurred (shown in Fig 14) the "ears" on the $\mathrm{n}_{\mathrm{e}}$ profile were completely lost, reducing $\mathrm{n}_{\mathrm{e}}$ at the edge (e.g. $\mathrm{R} \sim 1.40 \mathrm{~m}$ ) to $\sim 50 \%$ of its prior H-mode value. The magnitude and radial extent of the ELM perturbation were also reflected in USXR array emissivity. The emissivity in a broad shell fell to essentially zero; only a $15 \mathrm{~cm}$ radius region of the core was unaffected as seen in Figure 14 (e)

A stability analysis [26, 27] (Fig. 15) of a similar discharge showed the plasma to be high-n ballooning unstable and low-n stable before some giant ELMs. A large fraction of the plasma was high-n ballooning unstable just before the final ELM [Fig. 15(c)]. In addition, the plasma was low-n kink unstable without a wall, but stable in the presence of the NSTX 
conducting wall. It is likely therefore that high-n ballooning was responsible for the instability.

\section{Summary and Conclusion:}

The NSTX H-modes enabled access to reproducible high performance plasmas with separately achieved H-phase durations $>500 \mathrm{~ms}$ and $\beta_{\mathrm{T}}$ up to $35 \%$. Both L-mode and H-

mode confinement were enhanced relative to the $\tau_{\mathrm{E}}{ }^{97 \mathrm{~L}}$ scaling, having a nominal enhancement factor of $\mathrm{H}_{97 \mathrm{~L}} \sim 1.5$, ranging from 0.75 to 2.5 times the $97 \mathrm{~L}$ scaling.

The NSTX H-modes were found to have similarities to those of conventional aspect ratio tokamaks, with some notable exceptions. The H-mode power threshold in NSTX was found to be 2.5 to 6 times higher than a recent international scaling [15]. There was a clear $\mathrm{I}_{\mathrm{p}}$ dependence of the power threshold for the L-H transition, and this was different from conventional aspect ratio tokamaks. ELM behavior was dependent on configuration and fueling and a wide variation in ELM characteristics was observed. Fluctuation levels were reduced in the SOL and at the steep gradient region of the $n_{e}$ profile at the transition. This is consistent with an edge transport barrier. Thus, routine access to H-modes is facilitating studies of high $\beta$ and long pulse in NSTX.

\section{Figure Captions:}

Figure 1 The parameter ranges for the NSTX H-mode access space. 1(a) $B_{T}$ vs $I_{p}$ and 1(b) $\mathrm{P}_{\mathrm{NBI}}$ vs $\mathrm{n}_{\mathrm{e}}$ at the time of the L-H transition time. 
Figure 2 Time variation of parameters for a long pulse H-mode. Including; 2(a) machine parameters $\mathrm{I}_{\mathrm{p}}$ and $\mathrm{P}_{\mathrm{NBI}}, 2(\mathrm{~b})$ plasma parameters $\mathrm{n}_{\mathrm{e}}, \mathrm{P}_{\text {rad }}$, and $\mathrm{D}_{\alpha}$ and 2(c) performance parameters $\mathrm{W}_{\mathrm{MHD}}$ and enhancement factor over L-mode, $\mathrm{H}$.

Figure 3 Time evolution of $n_{e}$ and $T_{e}$ profiles for the long pulse plasma of Fig. 2.

Figure 4 Comparison of confinement in NSTX to that for the ITER EPS97-L-mode scaling. The average for the NSTX H-mode is $1.5 \times$ EPS97-L-mode, and ranges from 0.75 to 2.5 times the L-mode scaling.

Figure 5 Parameters for a high performance L-mode plasma in which an L-H transition occurs late in the discharge (at $\mathrm{t}=0.34 \mathrm{~s}$ ).

Figure 6 Comparison of profiles for the L-mode just before the transition with the H-mode shortly after the transition. The ion channel $\left(\mathrm{T}_{\mathrm{i}}, \mathrm{V}_{\phi}\right)$ was affected significantly.

Figure 7 Time variation of parameters for a beam power scan at $I_{p}=900 \mathrm{kA}$ and $B_{T}=0.45$ T.

Figure 8 Time variation of parameters for threshold determination at two values of $\mathrm{I}_{\mathrm{p}} ; 600$ kA and $900 \mathrm{kA}$. The short H-phase occurs near the threshold in both cases.

Figure 9 A clear dependence of $\mathrm{P}_{\text {th }}$ on plasma current is shown in this plot of $\mathrm{P}_{\mathrm{Loss}} / \mathrm{P}_{\mathrm{th}, 1}$ vs $\mathrm{I}_{\mathrm{p}}$. Here, $\mathrm{P}_{\mathrm{LOSS}} \sim 3 \times \mathrm{P}_{\mathrm{th}, 1}$ at $\mathrm{I}_{\mathrm{p}}=0.6 \mathrm{MA}$. The red dots are shots that had L-H transitions and the solid blue squares are L-mode shots in which H-modes were not obtained.

Figure 10 Fluctuation spectra for L-mode and H-mode discharges from the broadband 6 to $26 \mathrm{GHz}$ reflectometer. The amplitude of fluctuations was much lower in the H-mode than in the L-mode. A coherent mode centered at $\sim 120 \mathrm{kHz}$ was clear in the H-mode spectrum.

Figure 11 Spectrograms from the fast scanning edge reflectometer for fluctuations before, during, and after the L-H transition. The fluctuations went away at the transition and except 
for a single ELM burst, remained suppressed, especially at the steep density gradient position in the plasma.

Figure 12 Variety of ELM behavior with configuration and operating parameters (a) ELMfree in LSN divertor, (b) Giant ELMs in LSN divertor, and (c) ELMs of modest amplitude and frequency in DN configuration.

Figure 13 Plot of ELM amplitude, $\Delta \mathrm{D}_{\alpha}$ versus ELM frequency $v_{\mathrm{ELM}}$.

Figure 14 Parameters and profiles for a Giant ELM showing effect extends deep into the plasma core.

Figure 15 Results of a stability analysis for a plasma with a train of four giant ELMs. Plasma was high-n ballooning unstable just before the 4th ELM but stable after the ELM. The $\mathrm{n}=1$ kink mode was wall stabilized and not responsible for the ELM. 


\section{References:}

1) Neumeyer, C., et al., Fusion Eng. and Design 54 (2001) 275.

2) Bush, C.E., et al., Proc. of 29th Euro. Conf. on Plasma Phys. and Contr. Fusion, Montreaux, SZ, June 17-22, 2002.

3) Maingi, R., et al., ICPP paper

4) Mueller, D., et al., Proc. 29th International Conference on Plasma Science, Alberta, CA, June 17-22, 2002 in press.

5) Gates, D.A., et al., invited paper at this APS.

6) LeBlanc, B., et al., IAEA 2002 paper

7) Kugel, H.W., et al., "Impact of Wall Conditioning Program on Plasma Performance in NSTX", J. Nucl. Mater. in press.

8) Field, A.R., et al., Plasma Phys. Contr. Fusion 44 (2002) A113.

9) Maingi, R., et al., IAEA 2002 paper.

10) ITER Physics Basis Editors, Nuc. Fusion 39 (1999) 2175.

11) Maingi, R., et al., Phys. Rev. Letts. 88 (21 Jan. 2002) 035003.

12) Bush, C.E., et al., Plasma Phys. and Contr Fusion, 44 (2002) A323.

13) Sykes,A., et al., Phys. Plasmas 8 (2001) 2101.

14 Snipes, J.A., et al., Proc. 24th Euro. Conf. on Plasma Physics and Contr. Fusion,Berchtesgaden, Germany (1997: Geneva), part III, p. 961.

15) Snipes, J. A., et al., IAEA 2002 paper

16) Kaye, S.M., et al., in preparation, 2003.

17) Rogers, B.N. and Drake, J.F., Phys. Rev. Lett. 79 (1997) 229.

18) Connor, J.W., Hastie, R.J., Wilson, H.R., Phys. Plasmas 5 (1998) 2687. 
19) Pogutse, O., et al., in Controlled Fusion and Plasma Physics (Proc. $24^{\text {th }}$ Eur. Conf. Berchtesgaden, 1997), Vol. 21A, Part III, European Physical Society, Geneva (1997) 1545.

20) Maqueda, R., et al., Proc. 14th High Temp. Plasma Diagnostics Conf., Madison, WI, 8-11 July, 2002.

21) Wilgen, J. B., et al., Bull. Am. Phys. Soc. 46, No. 8, p. 259 (2001)

22) Kubota, S., Nguyen, X.V., Peebles, W.A., Zeng, L., Doyle, E.J., Rev. Sci, Instrum. 72 (2001) 348 .

23) Princeton Scientific Instruments, www.prinsci.com

24) Terry, J., et al, C-mod invited paper at this APS

25) Boedo, J., et al., DIII-D invited paper at this APS.

26) Sabbagh, S.A., et al., Phys. Plasmas, 9 (2002) 2085.

27) Glasser, A.H. and Chance, M.S., Bull. Am. Phys. Soc. 42 (1997) 1848. 
Fig.1
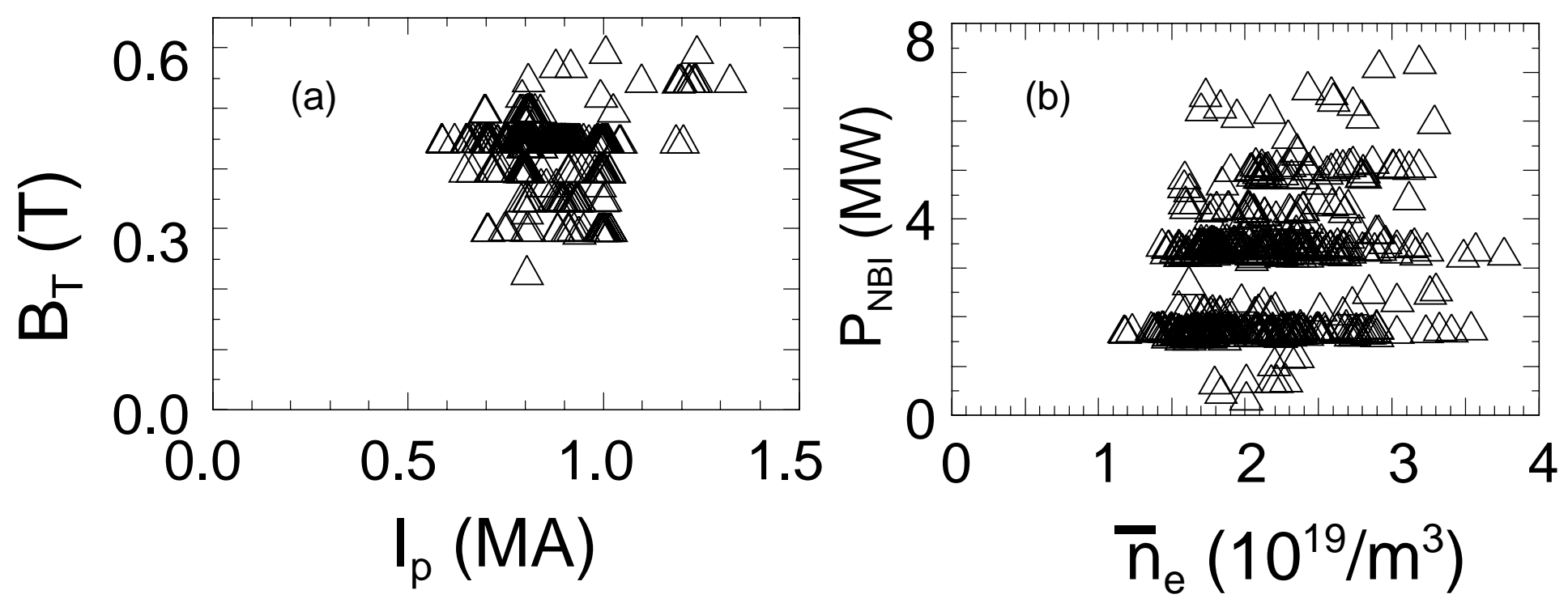
Fig 2

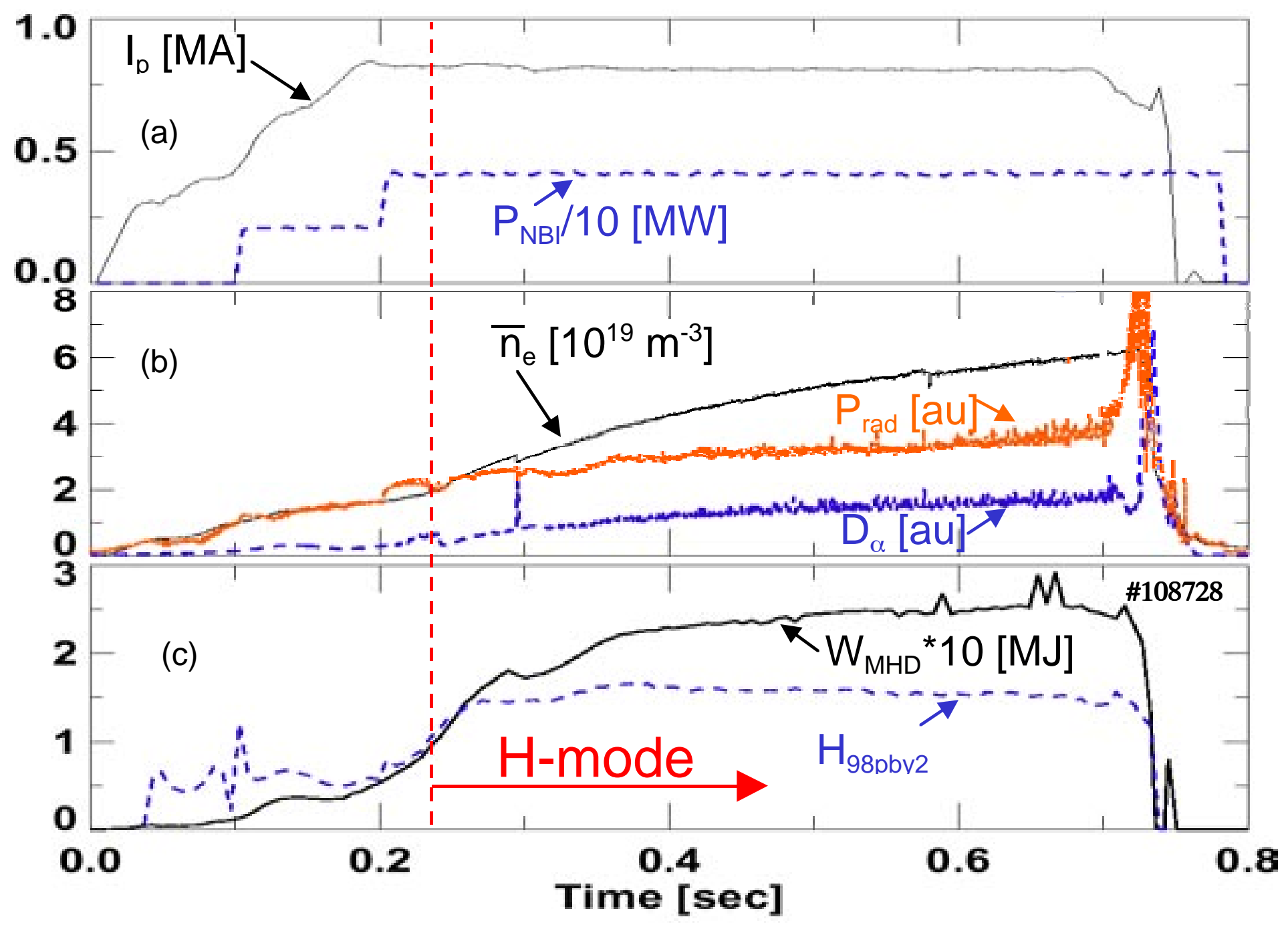


Fig 3

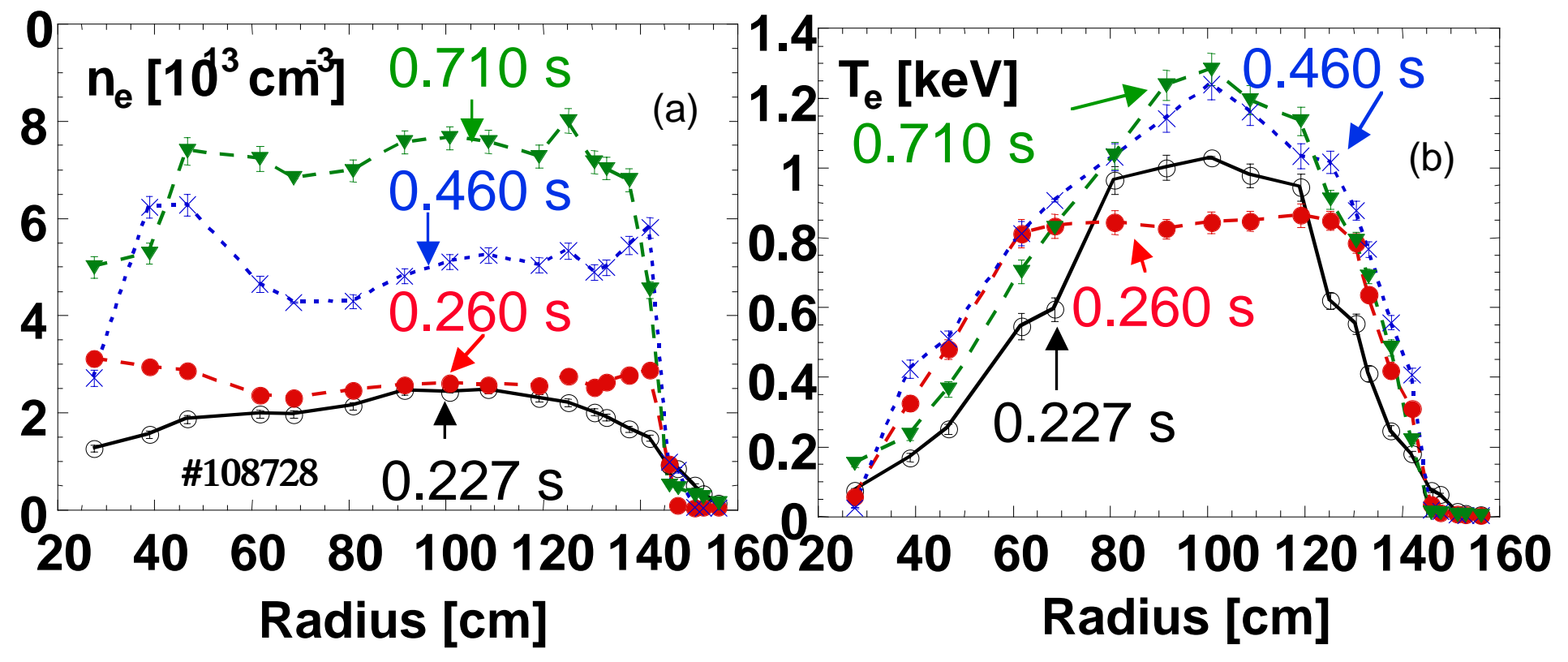


Fig 4

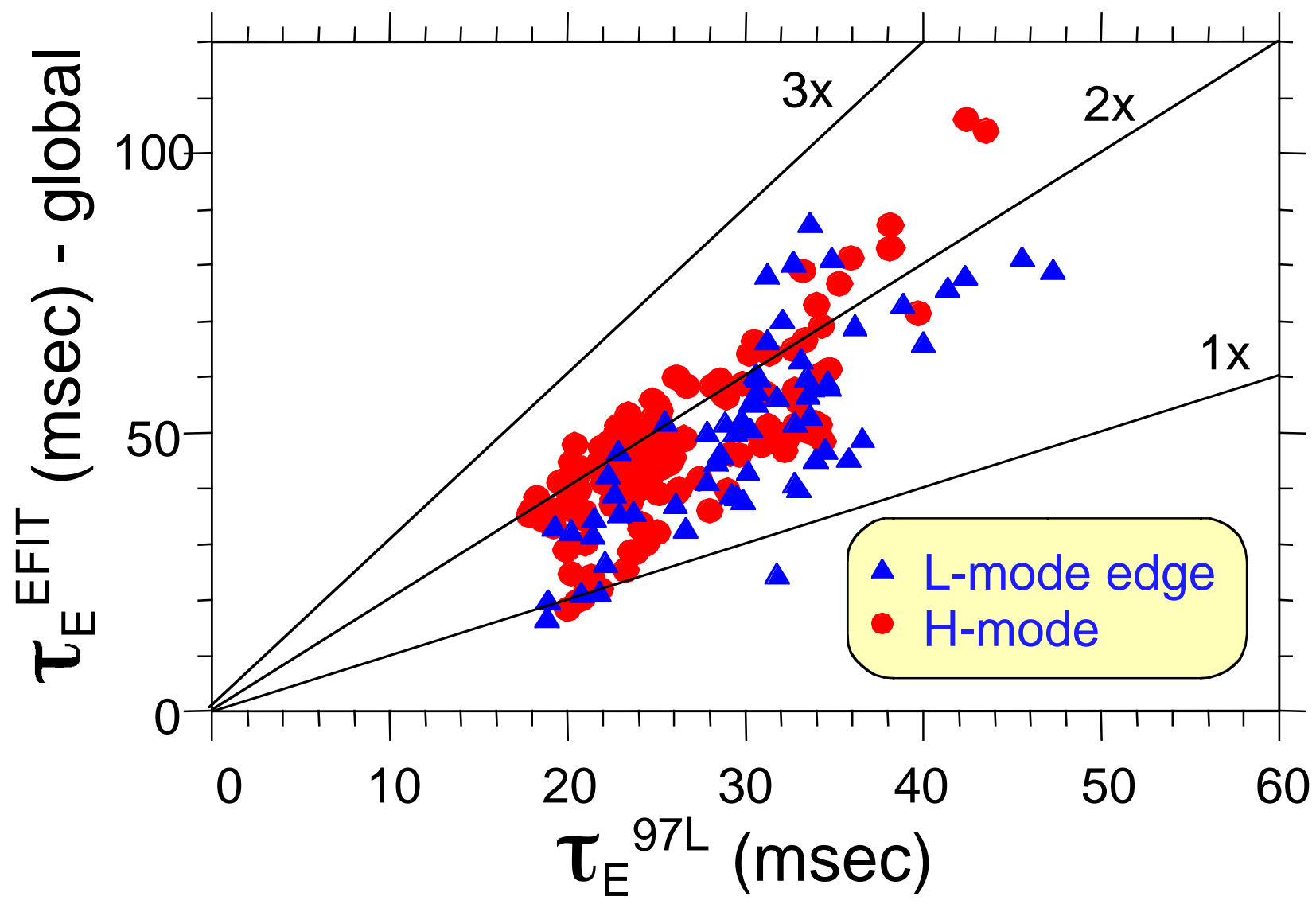


Fig 5

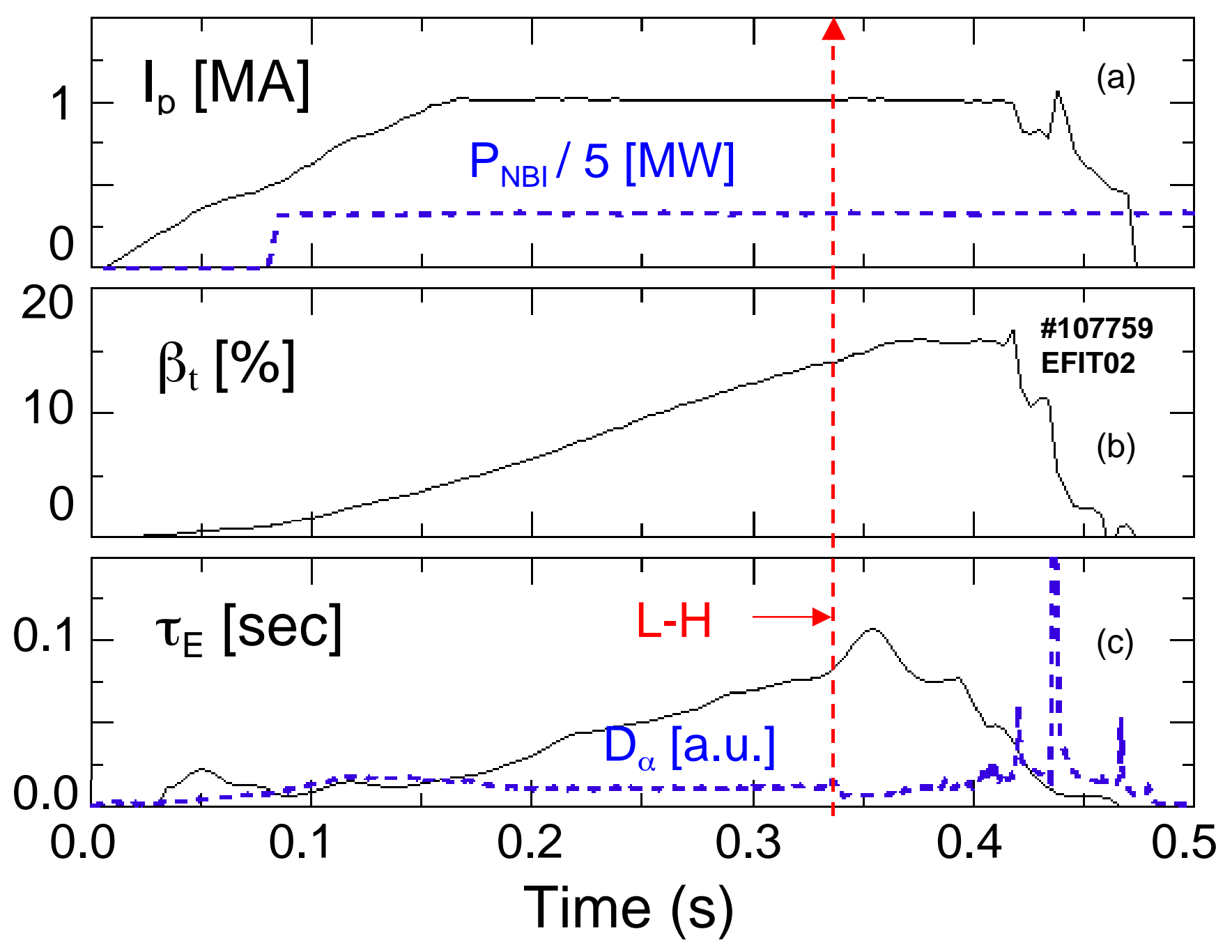


Fig 6
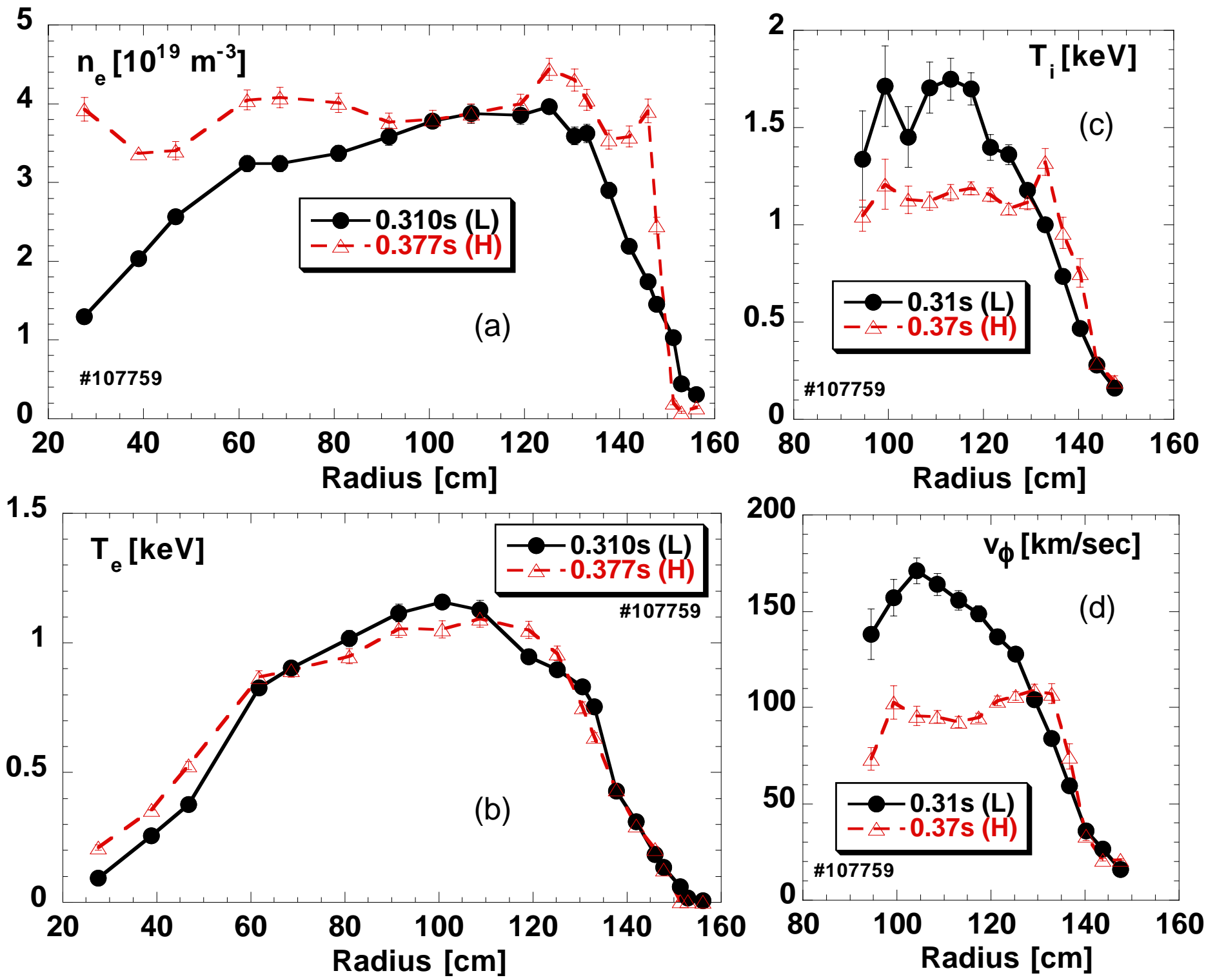
Fig 7
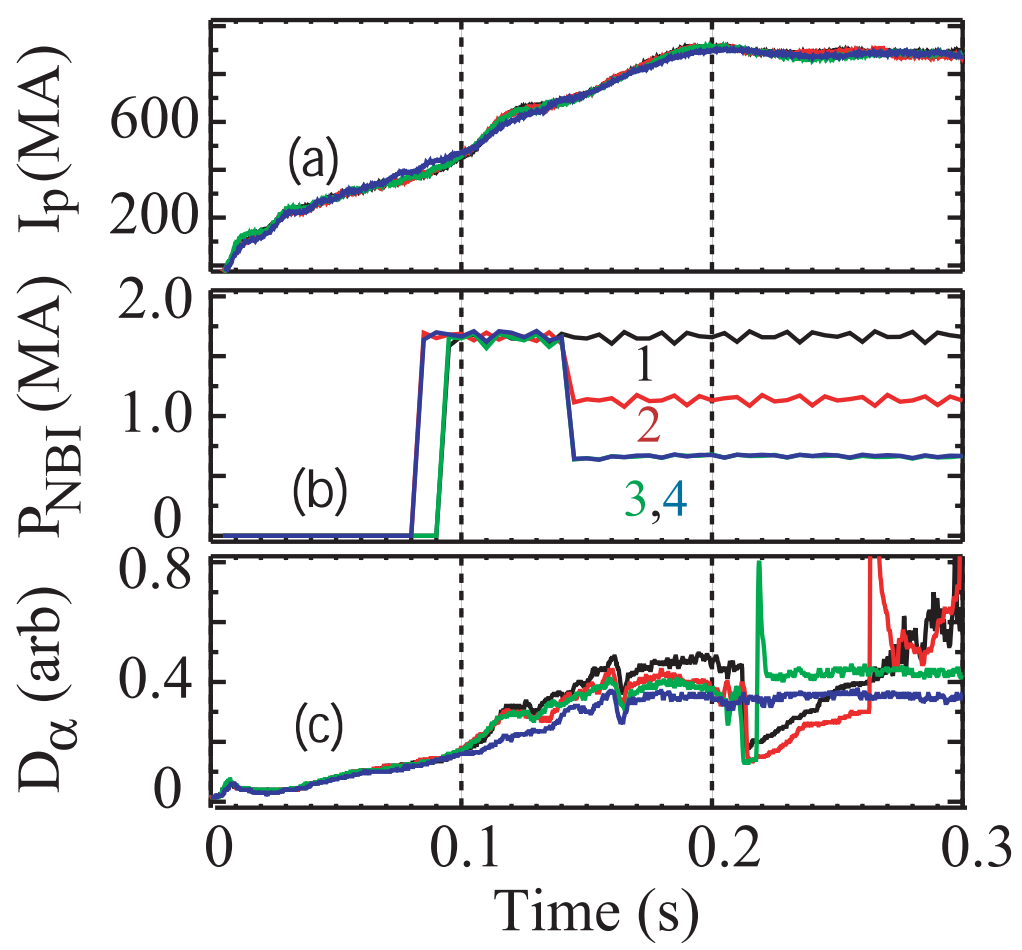
Fig 8
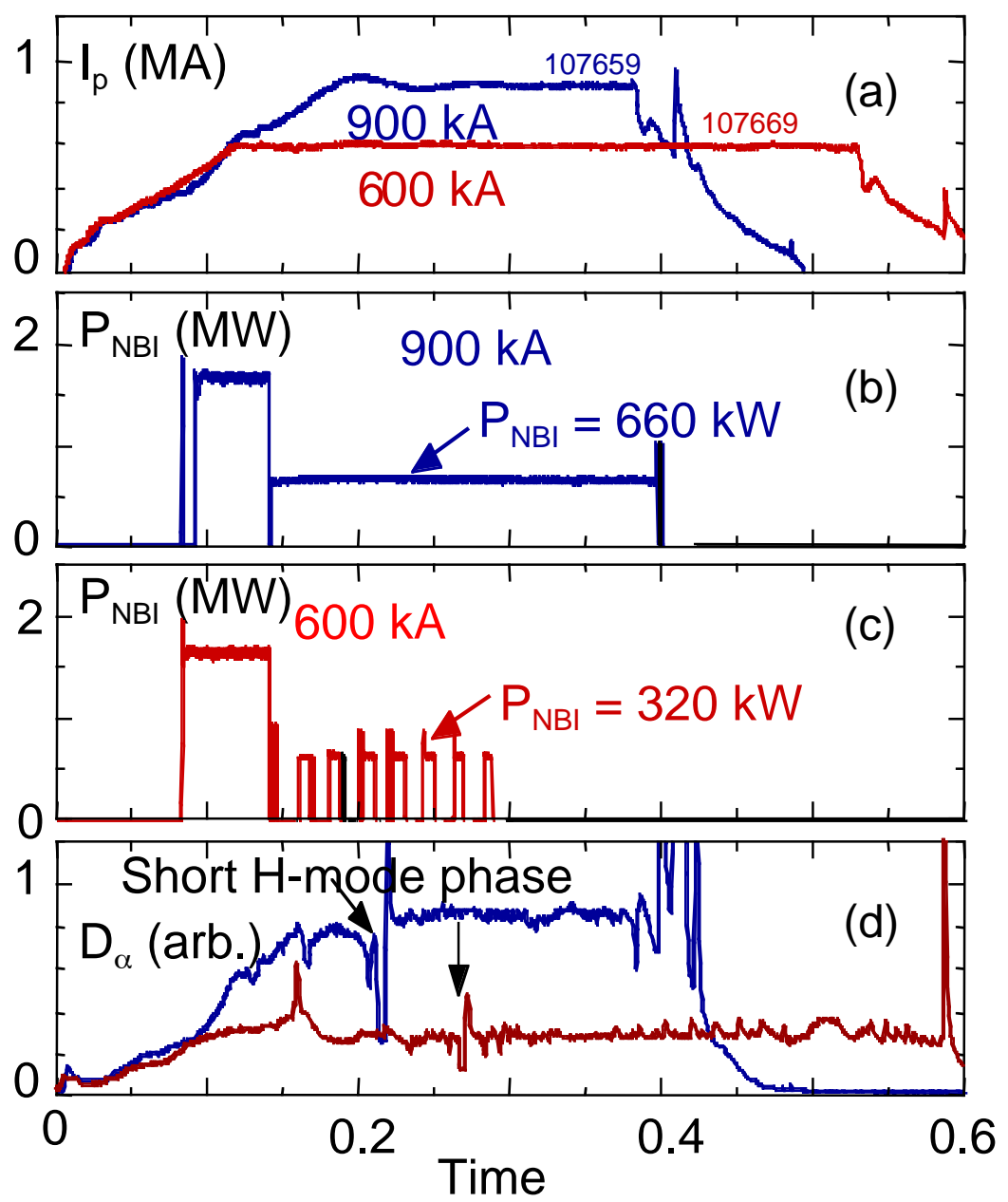
Fig 9

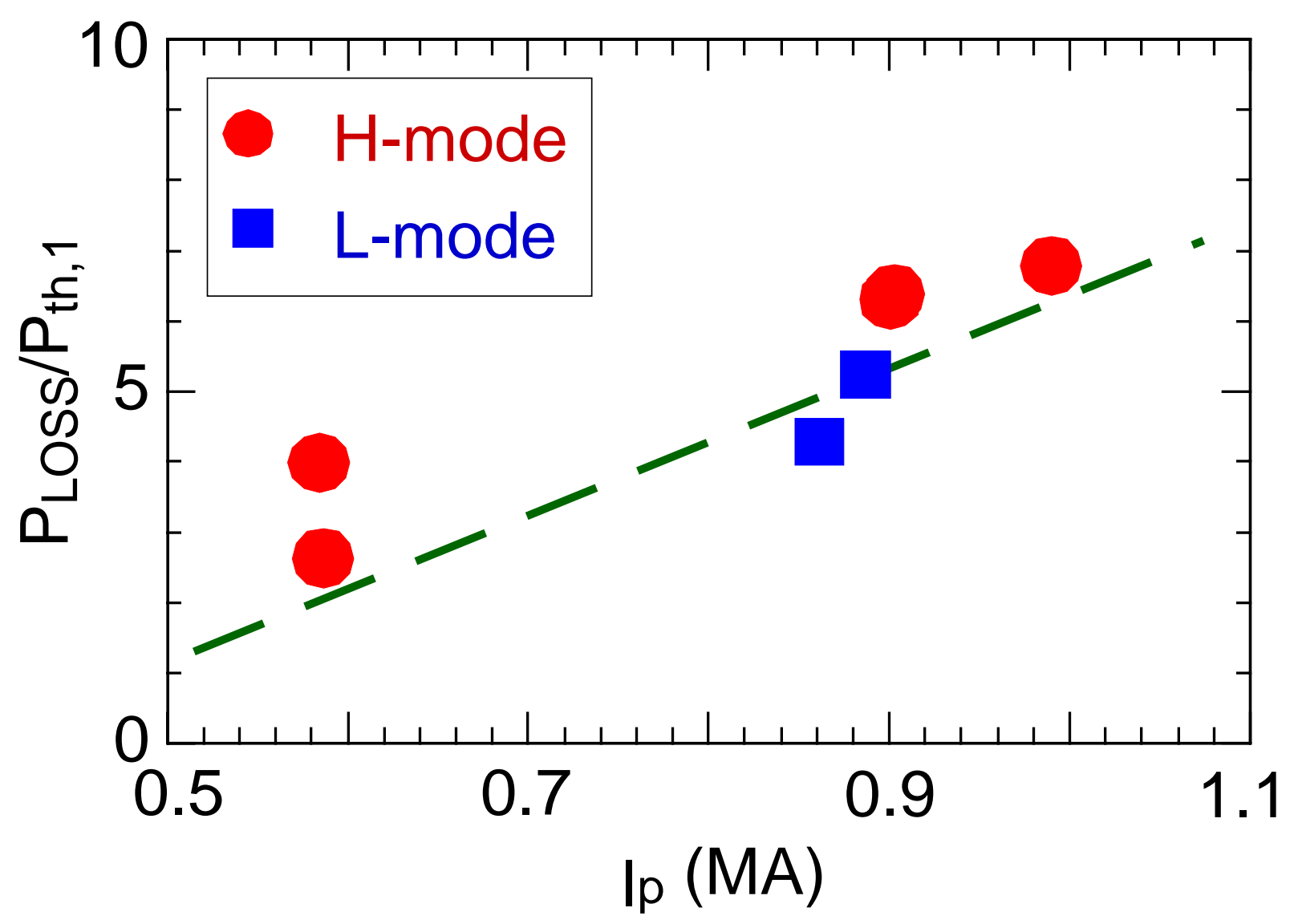


Fig 10

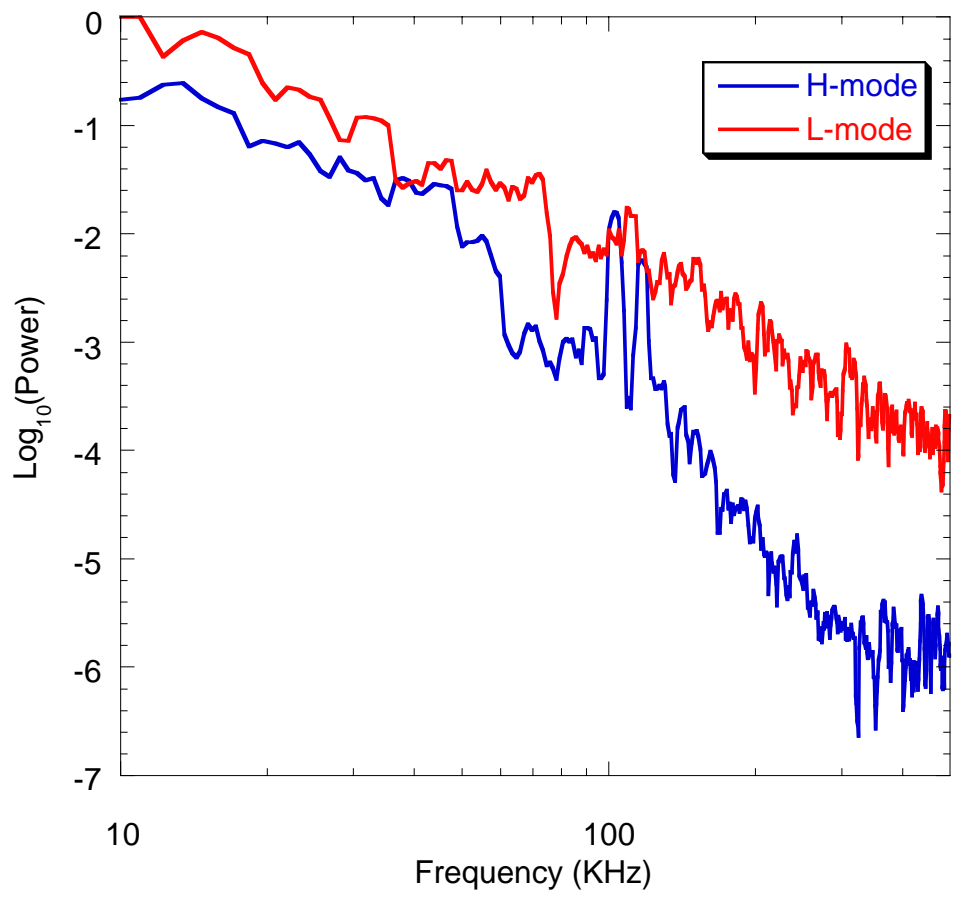


Fig 11
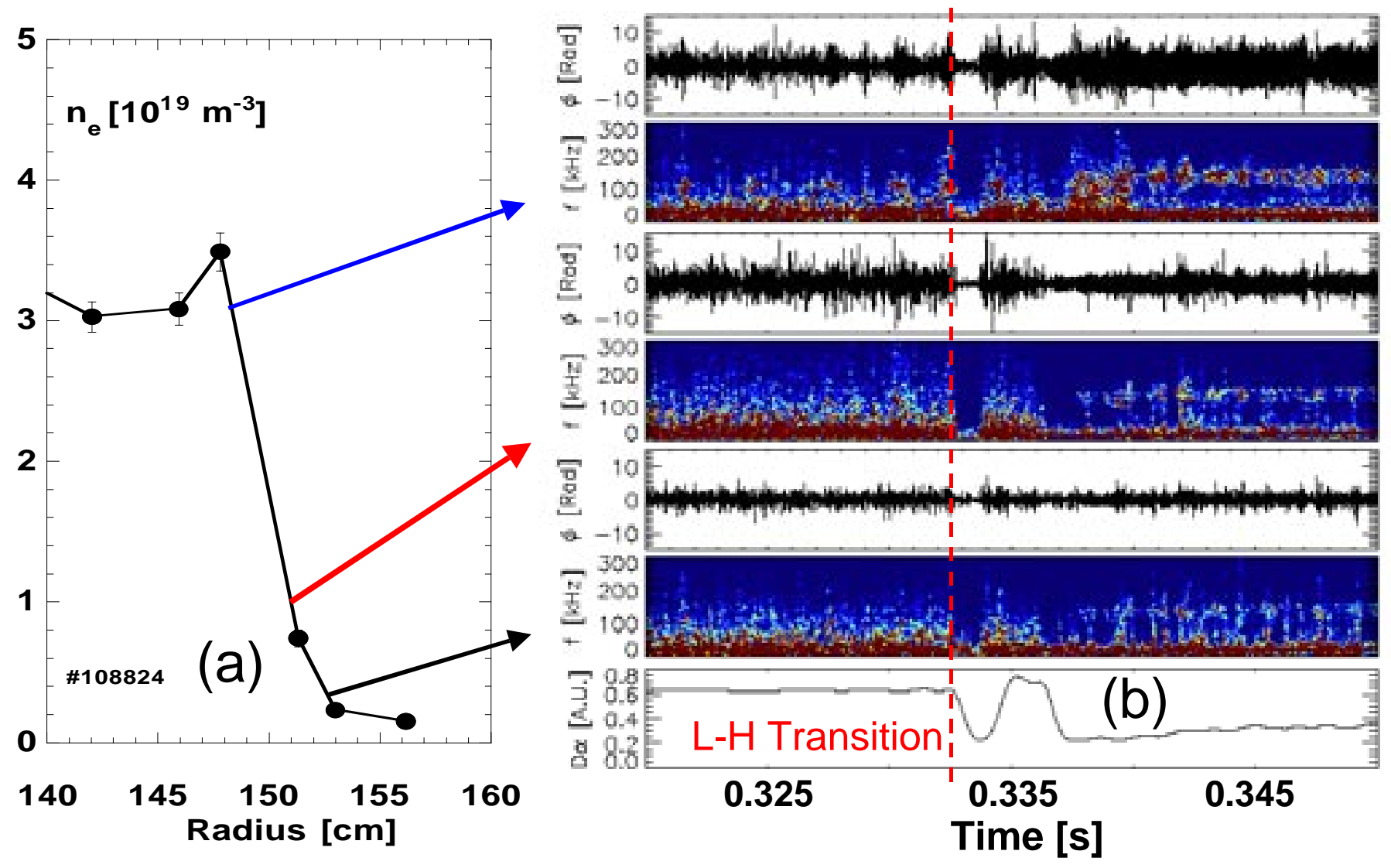
Fig 12

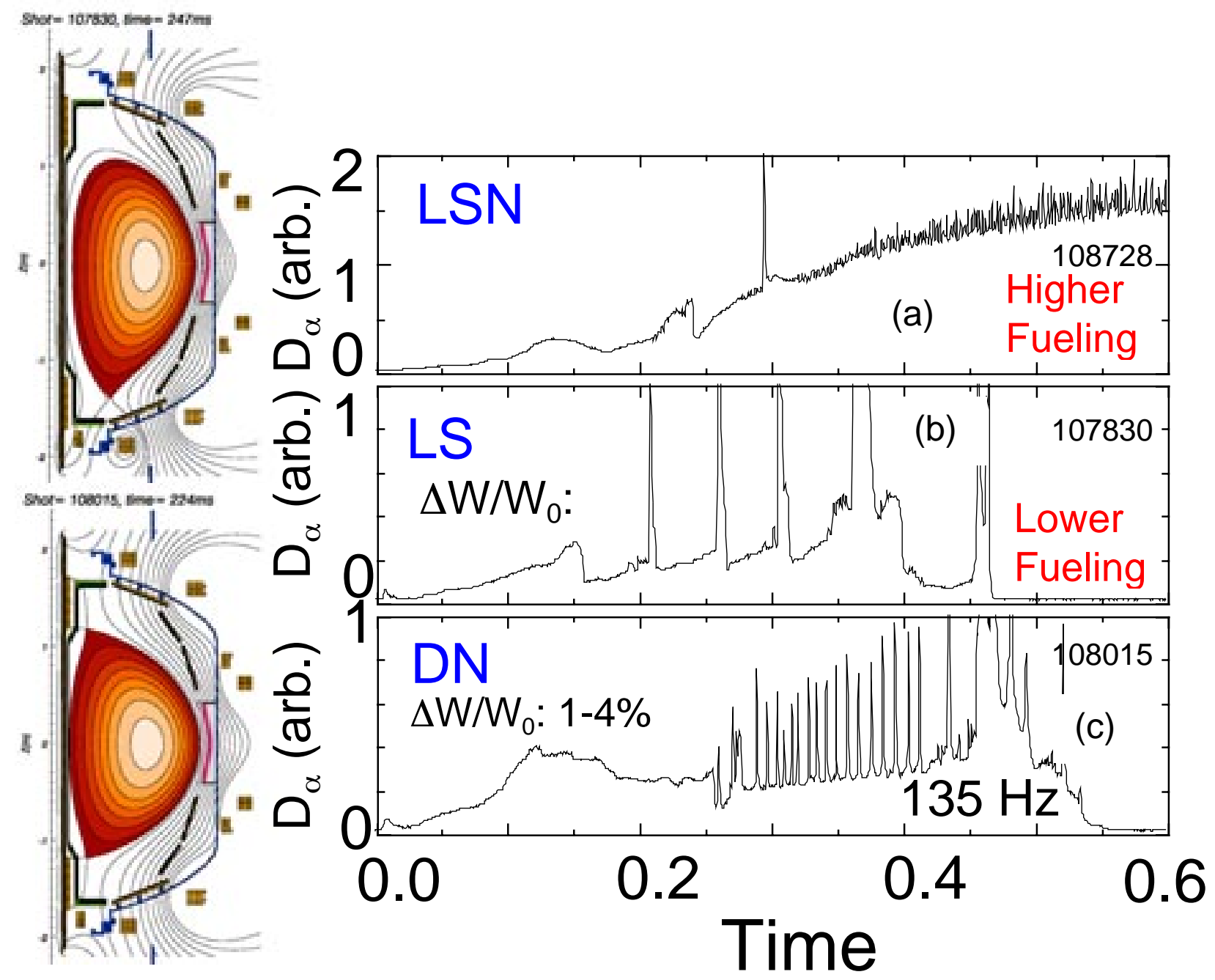


Fig 13

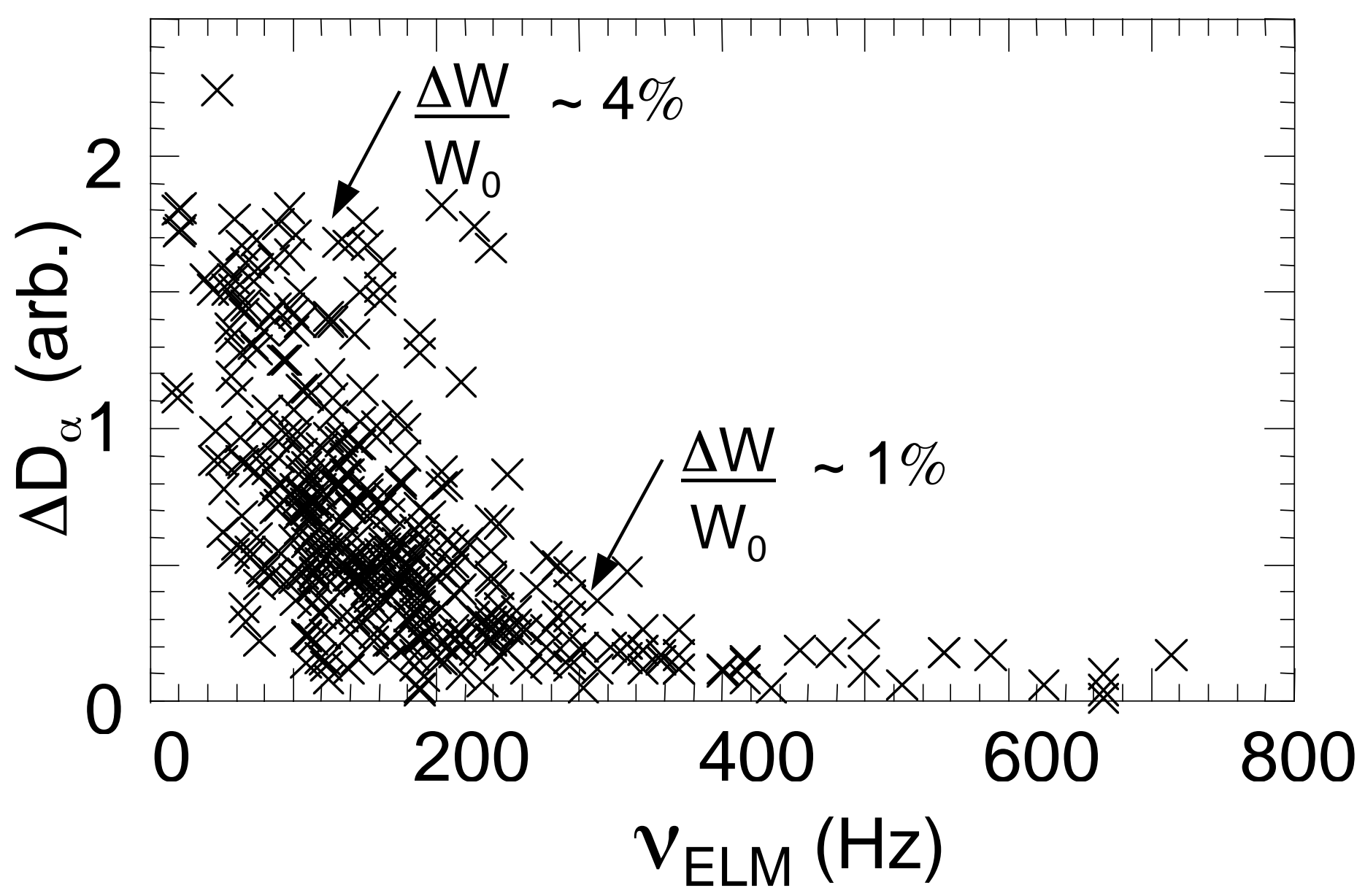


Fig 14

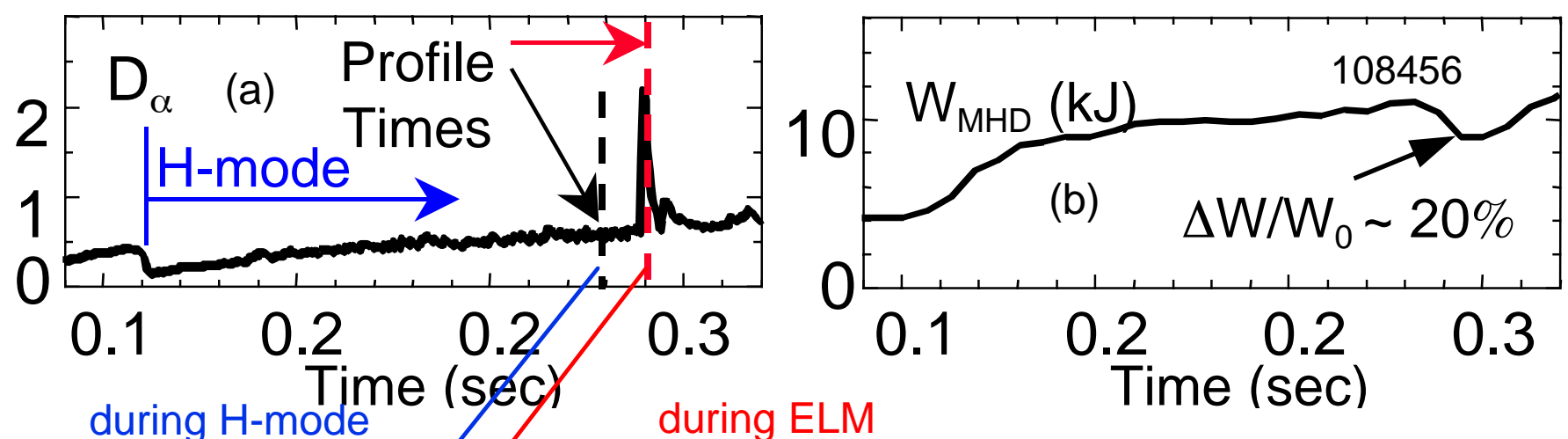

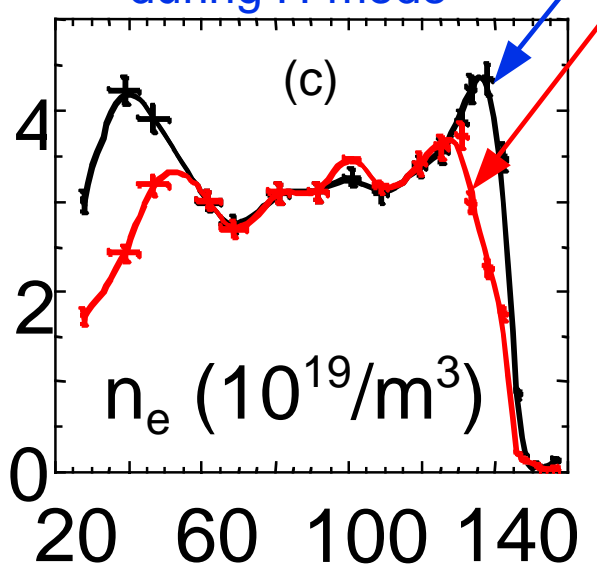

Radius

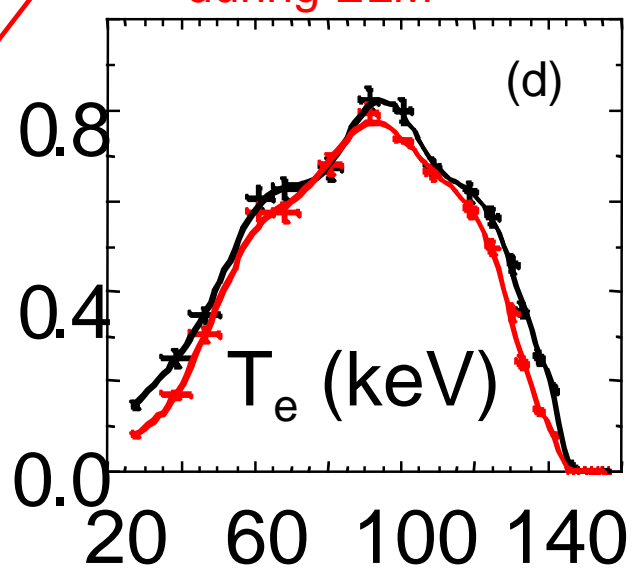

Radius

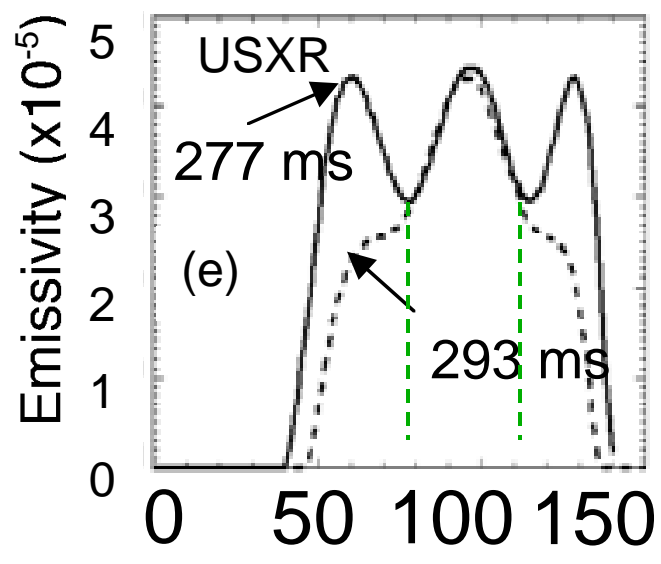

Radius 
Fig 15

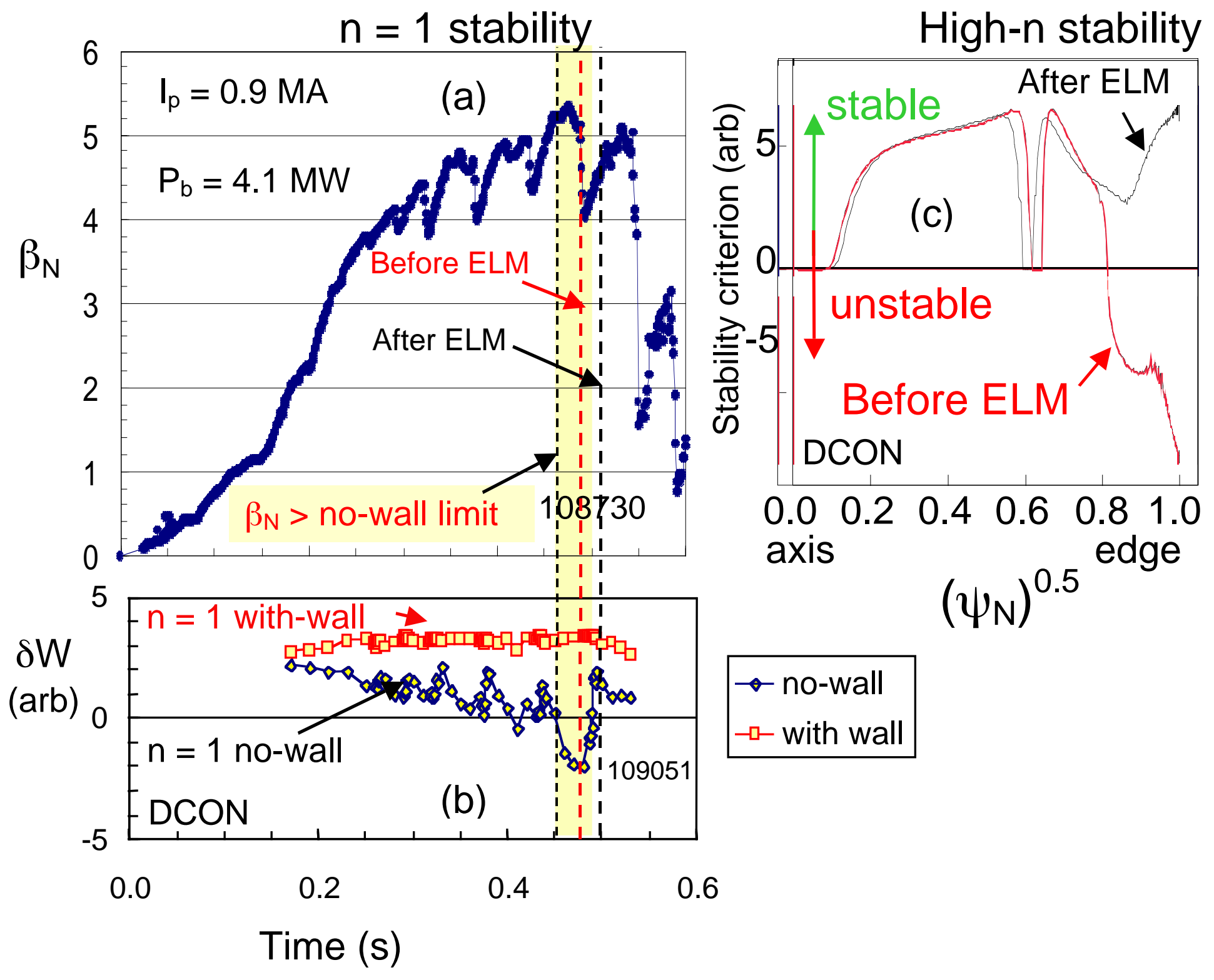




\section{External Distribution}

Plasma Research Laboratory, Australian National University, Australia

Professor I.R. Jones, Flinders University, Australia

Professor João Canalle, Instituto de Fisica DEQ/IF - UERJ, Brazil

Mr. Gerson O. Ludwig, Instituto Nacional de Pesquisas, Brazil

Dr. P.H. Sakanaka, Instituto Fisica, Brazil

The Librarian, Culham Laboratory, England

Mrs. S.A. Hutchinson, JET Library, England

Professor M.N. Bussac, Ecole Polytechnique, France

Librarian, Max-Planck-Institut für Plasmaphysik, Germany

Jolan Moldvai, Reports Library, MTA KFKI-ATKI, Hungary

Dr. P. Kaw, Institute for Plasma Research, India

Ms. P.J. Pathak, Librarian, Insitute for Plasma Research, India

Ms. Clelia De Palo, Associazione EURATOM-ENEA, Italy

Dr. G. Grosso, Instituto di Fisica del Plasma, Italy

Librarian, Naka Fusion Research Establishment, JAERI, Japan

Library, Plasma Physics Laboratory, Kyoto University, Japan

Research Information Center, National Institute for Fusion Science, Japan

Dr. O. Mitarai, Kyushu Tokai University, Japan

Library, Academia Sinica, Institute of Plasma Physics, People's Republic of China

Shih-Tung Tsai, Institute of Physics, Chinese Academy of Sciences, People's Republic of China

Dr. S. Mirnov, TRINITI, Troitsk, Russian Federation, Russia

Dr. V.S. Strelkov, Kurchatov Institute, Russian Federation, Russia

Professor Peter Lukac, Katedra Fyziky Plazmy MFF UK, Mlynska dolina F-2, Komenskeho Univerzita, SK-842 15 Bratislava, Slovakia

Dr. G.S. Lee, Korea Basic Science Institute, South Korea

Institute for Plasma Research, University of Maryland, USA

Librarian, Fusion Energy Division, Oak Ridge National Laboratory, USA

Librarian, Institute of Fusion Studies, University of Texas, USA

Librarian, Magnetic Fusion Program, Lawrence Livermore National Laboratory, USA

Library, General Atomics, USA

Plasma Physics Group, Fusion Energy Research Program, University of California at San Diego, USA

Plasma Physics Library, Columbia University, USA

Alkesh Punjabi, Center for Fusion Research and Training, Hampton University, USA

Dr. W.M. Stacey, Fusion Research Center, Georgia Institute of Technology, USA

Dr. John Willis, U.S. Department of Energy, Office of Fusion Energy Sciences, USA

Mr. Paul H. Wright, Indianapolis, Indiana, USA 
The Princeton Plasma Physics Laboratory is operated by Princeton University under contract with the U.S. Department of Energy.

\author{
Information Services \\ Princeton Plasma Physics Laboratory \\ P.O. Box 451 \\ Princeton, NJ 08543
}

Phone: 609-243-2750

Fax: 609-243-2751

e-mail: pppl_info@pppl.gov

Internet Address: http://www.pppl.gov 